\title{
FUTUROS PROFESSORES: EXERGAMES COMO RECURSO EDUCACIONAL
}

Loiane Maria Zengo, Manoel Osmar Seabra Junior, Jaqueline Costa Castilho Moreira

Universidade Estadual Paulista - FCT/UNESP. Curso de Educação Física, Presidente Prudente - SP. E-mail: lozengo@hotmail.com

\section{RESUMO}

O objetivo deste estudo foi investigar os Exergames como recursos educacionais no intuito de instrumentalizar futuros professores de Educação Física em suas práticas pedagógicas. Utilizou a metodologia denominada "pesquisação", realizada com um grupo de cinco graduandos que vivenciaram o pacote Kinect Adventures do X-box 360 com Kinect. Por tratar-se de formação docente, durante e após as vivências, o grupo pesquisado elencou a possibilidade de se desenvolver por meio dos jogos um repertório de capacidades, habilidades e algumas competências; discutiu sobre elementos dos jogos que colaboram com aspectos pedagógicos e constatou alguns procedimentos didáticos para uma melhor realização do Exergame. Concluiu-se que o uso dos Exergames nas aulas de Educação Física é possível e pode ser considerado como um recurso inovador e altamente motivante no processo de ensino e de aprendizagem escolar.

Palavras-chave: Exergame. Recurso educacional. Educação Física. Formação docente. X-Box 360.

\section{FUTURE TEACHERS: EXERGAMES AS AN EDUCATIONAL RESOURCE}

\begin{abstract}
The aim of this study was to investigate the Exergames as educational resources in order to equip future Physical Education teachers in their teaching practices. Used as a methodology called "pesquisação" held with a group of five graduate students who experienced the Kinect Adventures to the $X$-box 360 with Kinect. Because it is Teacher training, during and after the experience, the research group has listed the possibility of developing games through a repertoire of skills, abilities, and some competences; discussed elements of games that work with pedagogical aspects and found some didactics procedures to better realization the Exergames. It was concluded that the use of Exergames in Physical Education is possible and can be considered as an innovative and highly motivating resource in teaching and school learning process.

Keywords: Exergames. Educational Resource. Physical Education. Teacher training. X-Box 360.
\end{abstract}




\section{INTRODUÇÃO}

O desenvolvimento técnico-científico tem propiciado transformações relevantes na sociedade contemporânea, facilitando e melhorando a vida das pessoas. A sedução de seus benefícios gera outras formas de pensar, de comparar e de incorporar a modernidade (FEENBERG,1995).

Concorda-se com Pinheiro et al. (2007) sobre a necessidade das pessoas em ter condições de avaliar o impacto do avanço técnico-científico e a evolução de suas criações e aplicações no entorno. O autor ressalta a importância do protagonismo desses sujeitos nas decisões de adesão, resistência ou apatia quanto à tecnologia, já que estas atingem suas vidas. A adequada participação vem com o debate e a negociação dos direitos da vez e da voz.

Levar as discussões sobre ciência, tecnologia e sociedade no âmbito do Ensino Básico tem sido um dos aspectos difundidos pelos Parâmetros Curriculares Nacionais (PCNs). O direcionamento da educação tecnológica proposta é mais voltado para a compreensão da origem e do uso que a sociedade faz dos artefatos e recursos, do que propriamente para sua confecção ou mesmo para reflexões amplificadas sobre a desigualdade a seu acesso (PINHEIRO; SILVEIRA; BAZZO, 2007). A expectativa sobre o desenvolvimento da temática no currículo oficial não é somente quanto à inclusão dos estudantes na cultura digital globalizada. Está relacionada também ao preparo dos futuros professores e da atualização e aperfeiçoamento daqueles que estão em exercício.

Na perspectiva da Educação Física, há um consenso entre autores de diferentes áreas sobre as influências de se expor à virtualização, questionando a repercussão dessas novas representações do corpo na cultura contemporânea do movimento (LÉVY, 1996; FERES NETO, 2005; COSTA; BETTI, 2006; BARACHO; GRIPP; LIMA, 2012; SILVA; BRACCIALLI, 2013; SILVA, 2014). No currículo estadual paulista, desde 2009 o tema é inserido nos Cadernos de Educação Física dos alunos e professores distribuídos para o Ensino Médio (SÃO PAULO, 2009). A incorporação de discussões e vivências de jogos virtuais que apenas simulam movimento ("dança no tapete", pebolim, futebol de botão entre outros) perante aos jogos e aplicativos disponíveis aos alunos por meio dos celulares; representa um desafio aos professores.

Analisando a literatura existente sobre os jogos de natureza Full Body Gaming ou Exergames (EXG) que são uma combinação entre games e exercícios físicos propondo o "mover-se para jogar" (VAGHETTI; BOTELHO, 2010; BARACHO; GRIPP; LIMA, 2012), percebe-se diversas lacunas em sua utilização como recurso pedagógico na Educação Física. 
Para Feres Neto (2005); Baracho, Gripp e Lima (2012) os obstáculos são a ausência de recursos financeiros para compra destas plataformas e disponibilização nas unidades; o anacronismo das escolas em relação às novas tecnologias; o estereótipo que vincula a virtualização do corpo à exclusão ou à reclusão, à agressividade, ao vício, ao sedentarismo e finalmente, a ausência ou inadequada formação docente para a condução e para o pleno desenvolvimento dos alunos utilizando as novas tecnologias.

Assim, este estudo tem por objetivo investigar os Exergames como recursos educacionais no intuito de instrumentalizar futuros professores de Educação Física em suas práticas pedagógicas.

\section{METODOLOGIA}

Foi utilizada a pesquisação, uma intervenção deliberada, iniciada em escala restrita, em um ambiente real da prática, com a dupla perspectiva de generalização do conhecimento adquirido e de transformação efetiva da realidade (ANDALOUSSI, 2004).

A pesquisação considera a voz do sujeito, sua perspectiva, não somente para registro, mas como parte da metodologia de investigação. Por meio do desenrolar de suas etapas, organiza as situações relevantes que emergem do processo, possibilita a autoformação e emancipação dos sujeitos da ação, criando compromisso com sua formação e desenvolvimento de procedimentos críticos e reflexivos (FRANCO, 2005).

O grupo investigado foi composto por cinco graduandos, os quais elucidaram sua participação por meio da assinatura do Termo de Consentimento Livre e Esclarecido para este estudo, que se encontra registrado sob o protocolo no 109/2010, do Comitê de Ética de Pesquisa. Tomando por base a vivência e reflexão sobre as práticas educativas com EXGs, o grupo preparou o ambiente físico para o uso do equipamento; testou os jogos e discutiu os pontos positivos e negativos de cada jogo em ações educativas.

Selecionou-se o pacote Kinect Adventures que possibilita a experimentação sem riscos de jogos exclusivos da Microsoft em simulações de esportes e de aventura. Justifica-se esta escolha pelo fato do pacote ser adquirido juntamente com o aparelho X-box 360 com Kinect e por ser indicado a qualquer faixa etária; fatores estes que colaboram com sua popularidade. Os jogos oferecidos no Kinect Adventures são: Bolha Espacial, Vazamento, Salão dos Ricochetes, Reflexos dos Cumes e Corredeiras.

A pesquisação foi composta por cinco sessões, com duração de duas horas e meia cada, com o propósito de que cada um dos pesquisados vivenciasse cada jogo como um futuro 
professor. O tempo destinado à sessão de jogos foi de uma hora e meia e o restante dividido na montagem e preparação inicial do equipamento e nas observações e reflexões. No decorrer do estudo também foram realizadas filmagens, fotografias e anotações sobre os comentários durante sua ocorrência nas intervenções. Todos os encontros foram realizados em uma sala específica da universidade, sendo que a discussão final foi gravada em áudio com uso de celular e transcrita.

\section{RESULTADOS}

Por tratar-se de um estudo com intuito de formação docente em Educação Física, durante e após as vivências, o grupo elencou um repertório de capacidades e habilidades (SCHIMIDT; WRISBERG, 2001) e competências (PERRENOUD, 1999) desenvolvidas nos jogos; discutiu sobre elementos dos EXGs que colaboram com aspectos pedagógicos e constatou alguns procedimentos didáticos para uma melhor realização do EXG, conforme o quadro 1:

Quadro 1. Observações constatadas após a realização dos jogos do pacote Kinect Advertures.

\begin{tabular}{|c|c|c|c|c|}
\hline Pacote & $\begin{array}{c}\text { Jogos do } \\
\text { Pacote }\end{array}$ & $\begin{array}{l}\text { Capacidades, habilidades e } \\
\text { competências propiciadas }\end{array}$ & $\begin{array}{l}\text { Elementos dos jogos } \\
\text { que colaboram com } \\
\text { aspectos pedagógicos }\end{array}$ & $\begin{array}{c}\text { Indicação de } \\
\text { Procedimentos } \\
\text { Didáticos }\end{array}$ \\
\hline \multirow{5}{*}{$\begin{array}{c}\text { Kinect } \\
\text { Adventure } \\
s\end{array}$} & $\begin{array}{c}\text { Bolha } \\
\text { Espacial } \\
\text { (individual) }\end{array}$ & \multirow{5}{*}{$\begin{array}{l}\text { - Agilidade; } \\
\text { - Concentração; } \\
\text { - Controle de Velocidade; } \\
\text { - Coordenação Manual; } \\
\text { - Coordenação óculo- } \\
\text { - pedal; } \\
\text { - Coordenação; } \\
\text { - Equilíbrio; } \\
\text { - Esquema Corporal; } \\
\text { - Força Dinâmica; } \\
\text { - Imagem corporal; } \\
\text { - Lateralidade, } \\
\text { - Orientação Espaço- } \\
\text { - temporal; } \\
\text { - Precisão de Controle; } \\
\text { - Reação e Resposta; } \\
\text { - Reflexo Espelho; } \\
\text { - Ritmo; } \\
\text { - Sincronização Motora; } \\
\text { - Tempo de Reação; } \\
\text { - Tônus Muscular; } \\
\text { - Identificação, } \\
\text { organização e } \\
\text { designação de } \\
\text { conhecimentos }\end{array}$} & \multirow{5}{*}{$\begin{array}{l}\text { - Ambiente virtual que } \\
\text { simula o desejo do } \\
\text { jogador a conhecer } \\
\text { ou vivenciar esportes } \\
\text { e aventura com baixo } \\
\text { custo financeiro ou } \\
\text { risco; } \\
\text { - Ambiente social real } \\
\text { que estimula a } \\
\text { adesão pelo lúdico e } \\
\text { pelas múltiplas } \\
\text { possibilidades de } \\
\text { experimentação; } \\
\text { - Desafios possíveis; } \\
\text { - Regras específicas } \\
\text { como o tempo e o } \\
\text { espaço para a ação } \\
\text { do jogador; } \\
\text { - Redução da } \\
\text { ansiedade em relação } \\
\text { ao erro ou ao } \\
\text { fracasso, o que } \\
\text { encoraja novas } \\
\text { tentativas; } \\
\text { - Interação entre }\end{array}$} & \multirow{5}{*}{$\begin{array}{l}\text { - Necessidade } \\
\text { de } \\
\text { Alongament } \\
\text { o pré e pós; } \\
\text { - Prévia } \\
\text { instrução } \\
\text { sobre } \\
\text { movimentos } \\
\text { essenciais } \\
\text { requeridos; } \\
\text { - Importância } \\
\text { da } \\
\text { delimitação } \\
\text { visual do } \\
\text { espaço de } \\
\text { jogo; } \\
\text { - Atenção ao } \\
\text { feedback; } \\
\text { - Reflexão } \\
\text { sobre as } \\
\text { estratégias, }\end{array}$} \\
\hline & $\begin{array}{c}\text { Corredeiras } \\
\text { (Cooperativo) }\end{array}$ & & & \\
\hline & $\begin{array}{l}\text { Reflexo dos } \\
\text { Cumes } \\
\text { (competitivo) }\end{array}$ & & & \\
\hline & $\begin{array}{c}\text { Salão dos } \\
\text { Ricochetes } \\
\text { (competitivo) }\end{array}$ & & & \\
\hline & & & & \\
\hline
\end{tabular}


pertinentes na tomada de decisões em uma situação;

- Mobilização destes conhecimentos com discernimento. pessoas diferentes,

mas que

compartilham um

forte grau de

afinidade: o jogar. os objetivos, o contexto, as formas do "jogar";

Embora no Kinect Adventures haja diferentes formas de interação (individuais, competitivas, cooperativas e online) e níveis de complexidade (easy, meddium e difficult), os participantes observaram que foram requeridas capacidades, habilidades e competências semelhantes. Cada jogo enfoca-as em estimulações específicas conforme suas propostas e cuja descriminação não cabe na brevidade deste artigo.

Da compilação de locuções sobre os elementos do EXG que colaboram com os aspectos pedagógicos, percebeu-se que o cenário dos jogos ou o ambiente de ação simulam de forma customizada, o visual de um local ou de uma vivência desejada de se experienciar, sem grandes riscos ou custos financeiros. Cada jogo apresenta desafios possíveis e regras específicas, bem como limita o tempo de ação do jogador e o espaço de movimentos por meio dos sensores. Além dessas normas implícitas, algumas regras de convivência são acordadas entre os participantes do momento, durante a dinâmica do jogar. A configuração de como e por quanto tempo o desafio será vivenciado, possibilita que o jogador direcione seus esforços e atenção, ou em linguagem coloquial "foque". O ambiente social lúdico e de múltiplas possibilidades que se forma, reduz a ansiedade em relação ao erro, permitindo que o condutor da vivência, no caso um professor, possa tratar os resultados obtidos pelo jogador com encorajamento, mesmo em jogos competitivos. Em relação a um dos jogos, o desafio factível e a sua repetição oportunizam um novo tentar; enquanto o pacote oferece outras opções, permitindo o contato dos participantes com vários tipos de desafios. Ao reunir diferentes pessoas, mas com mesma afinidade, o desejo do jogar forma grupos presenciais (e online), que na perspectiva de uma ação educativa, representa um importante momento de discussão de ideias, crenças, valores e formação de opiniões.

Quanto aos procedimentos didáticos, os graduandos apontaram que, anteriormente as vivências com os jogos fossem realizados alongamentos e instrução prévia sobre os movimentos essenciais requeridos em cada jogo. Durante os jogos, alertaram para o constante cuidado que os participantes devem tomar com a delimitação do espaço de jogo, em função da captura dos movimentos pelos sensores. Também foi assinalado por eles, a importância do feedback aos 
jogadores quanto aos movimentos, aos erros, às jogadas e ao escore obtido. Como procedimentos de encerramento, apontaram a relevância do alongamento final e da discussão coletiva.

\section{DISCUSSÃO}

Baseando-se nas ideias de Teixeira e Figueiredo (1970); Gee (2009), Feres Neto (2001), Silva e Bracciali (2013) e Silva (2014) discutiu-se os resultados da pesquisação. Além das informações disponíveis na embalagem como a natureza do jogo, o gênero e a indicação etária, outros aspectos devem ser considerados. Na classificação dos jogos de Teixeira e Figueiredo (1970), a proposta do pacote Adventures oscila na disponibilização de um game com funções gerais (jogos sensoriais, psíquicos, motores, afetivos) e especiais (jogos sociais e de luta/competição/discussão), tornando-o interessante pelos vários desafios (motores, cognitivos, sensoriais e sociais) para várias faixas etárias.

Já segundo Gee (2009) os elementos de qualificação para um bom jogo se definem: na imersão do participante no ambiente do jogo e sua identidade personificada no "avatar"; nos vários tipos de interação; na possibilidade de se criar outras formas de ação dentro do jogo, pelas ações que os participantes executam e pelas decisões que tomam; no modo de encarar o risco, os erros e o fracasso; nos níveis de dificuldade que permitem que os jogadores solucionem os problemas de diferentes maneiras; na oportunidade de gerenciar e controlar o jogo; no planejamento e na boa ordenação de problemas; na prática repetitiva do jogo que acaba gerando o ciclo da expertise; na questão de saber utilizar a "ação certa na hora certa" e ainda saber usar "ações extras" conquistadas como bônus; no sentido contextualizado do jogo; na frustração prazerosa; no pensamento sistemático; no pensamento lateral, exploração e revisão de objetivos; no conhecimento distribuído entre os pares; na formação de equipes transfuncionais e na experimentação do que o autor denomina como performance anterior à competência.

Correlacionando os elementos de Gee (2009) e a discussão do grupo sobre aqueles que aparecem no EXG e podem se tornar pedagógicos, tiveram destaque: a interação propiciada pelo visual do ambiente virtual e pelo design dos jogos; o encorajamento a correr riscos; as competências requeridas para gerir, planejar e controlar o jogo; o estimulo a se tornar um expert por meio da repetição; as ações essenciais tomadas na "hora certa" para garantia da continuidade do jogo; a possibilidade de aprimorar sua pontuação em um mesmo jogo devido à exequibilidade dos desafios; o estímulo ao pensamento estratégico durante o tempo de espera para se jogar novamente; a estimulação do pensamento lateral pelas múltiplas possibilidades de experimentação que o pacote Kinect Adventures oferece. Em contrapartida, outros elementos 
apontados em Gee (2009) inexistiram neste pacote de jogos, tais como uma tecnologia mais avançada para criação do próprio "avatar"; a possibilidade de se adaptar, modificar ou produzir novas alternativas nos jogos; a utilização de ações extras para o alcance de pontuações mais elevadas; a manipulação dos "avatares" com conhecimentos próprios emprestados ao jogador, denominadas de "ferramentas inteligentes do jogo"; a participação massiva de múltiplos jogadores em equipes transfuncionais.

Em relação aos procedimentos didáticos que o grupo apontou, Feres Neto (2001) acrescenta duas possibilidades de abordagem dos EXGs nas aulas de Educação Física, a mixagem e o estéreo. O conceito de mixagem se aplica como auxilio para a aprendizagem de técnicas e de movimentos específicos. O estéreo é caracterizado pelas discussões sobre a história, sentidos e significados dos jogos e modalidades esportivas e pelas reflexões, estratégias e feedcbacks do jogo. Em termos de mixagem, os jogos do Kinect cada um à sua maneira, propiciam o desenvolvimento de capacidades, habilidades e competências que podem ser aprimoradas por meio da intervenção docente durante a instrução prévia e no decorrer dos jogos. Quanto aos conteúdos do estéreo, eles podem ser tratados tanto antes como após a sessão de jogos, uma vez que o Adventure não oferece informações sobre as origens dos jogos, a história e outros possíveis temas para serem discutidos.

Complementando os procedimentos didáticos, Silva e Bracciali (2013) e Silva (2014) fazem apontamentos específicos e fornecem preciosas orientações a partir de suas práticas com videogames nas aulas de Educação Física de uma escola municipal de Ensino Fundamental I da rede regular. O diferencial das pesquisadoras foi oferecer aos vinte e três alunos vivências de modalidades esportivas de voleibol e futebol, em ambiente real e virtual, na forma de circuitos com estações de atividades com equipamentos e videogames. Essa estratégia pode ser facilmente incorporada tornado as aulas possíveis com pouco equipamento, além de motivantes e inovadoras.

\section{CONCLUSÃO}

O uso dos Exergames como recurso da Educação Física tem um efeito estimulador no desenvolvimento de capacidades e habilidades físicas e motoras e de competências cognitivas, afetivas e sociais. Permite a imersão em realidades de jogos e modalidades que nem sempre são possíveis no ambiente educacional; diversos níveis de interação, pensamento sistemático na tomada de decisão e solução de desafios, no reconhecimento de erros e no enfrentamento de situações novas. 
Ao se tratar do uso dos Exergames nas aulas de Educação Física, ele é possível e pode tornar os Exergames em recursos inovadores e altamente motivantes no processo de ensino e de aprendizagem escolar.

\section{REFERENCIAS}

ANDALOUSSI, K. EL. Pesquisas-ações: ciências; desenvolvimento, democracia. São Carlos: Edufscar. 2004.

BARACHO, A. F. O; GRIPP, F. J.; LIMA, M. R.. Os Exergames e a educação física escolar na cultura digital. Rev. Bras. Ciênc. Esporte, Porto Alegre, v. 34, n. 1, Mar. 2012. Disponível em $<$ http://www.scielo.br/scielo.php?script=sci_arttext\&pid=S0101$32892012000100009 \& \operatorname{lng}=e n \& n r m=i s o>$. Acesso em 12 jun. 2014.

COSTA, A.Q.; BETTI, M. Mídias e jogos: do virtual para uma experiência corporal educativa. Revista Brasileira de Ciências do Esporte, Campinas, v. 27, n. 2, jan. 2006. P. 165-78. Disponível em:< http://rbceonline.org.br/revista/index.php/RBCE/article/viewFile/100/109>.Acesso em 23 de fev. 2014.

FEENBERG, A. Technology and freedom. In: Alternative Modernity, Ekerley, Los Angeles: University of California Press, 1995.

FERES NETO, A. Videogame e Educação Física/Ciências do Esporte: uma abordagem à luz das teorias sobre o virtual. Lecturas Educación Física y Deportes, Buenos Aires, v. 10, n. 88, set. 2005. Disponível em: < http:// www.efdeportes.com/efd88/video.htm>. Acesso em 12 jun. 2014.

FRANCO, M.A.S. Pedagogia da Pesquisa-Ação. 2005. Rev. Educação e Pesquisa, São Paulo, v. 31, n. 3, p. 483-502, $\quad$ set./dez. $2005 . \quad$ Disponível $\quad$ em:< http://www.scielo.br/pdf/ep/v31n3/a11v31n3.pdf>. Acesso em 12 ago. 2014.

GEE, J. P. Bons videogames e boa aprendizagem. 2009. Disponível em:< https://periodicos.ufsc.br/index.php/perspectiva/article/view/2175795X.2009v27n1p167/14515>. Acesso em 16 jun. 2014.

LÉVY, P. O que é virtual? São Paulo: Editora 34, 1996.

PERRENOUD, P. Construir as competências desde a escola. Porto Alegre: Artmed, 1999.

PINHEIRO, N.A.M.; SILVEIRA, R.M.C.F.; BAZZO, W.A. Ciência, Tecnologia e Sociedade: a relevância do enfoque CTS para o contexto do Ensino Médio. Ciênc. educ. (Bauru) [online]. 2007, vol.13, n.1, pp. 71-84. Disponível em:<http://dx.doi.org/10.1590/S1516-73132007000100005>. Acesso em 18 jun. 2014.

SÃO PAULO (Estado) Secretaria de Educação. Caderno do professor: educação física, ensino médio - 3a série, volume 3. Secretaria de Educação; coordenação, M. I. FINI; EQUIPE J. DAÓLIO; L. VENÂNCIO; L. S. NETO; M. BETTI. São Paulo: SEE, 2009. 
SCHIMIDT, R. A. e WRISBERG, C. A aprendizagem e performance motora: Uma abordagem da aprendizagem baseada no problema. 2a ed. Porto Alegre: Artmed Editora, 2001.

SILVA, F.C.T.; BRACCIALLI, L.M.P. Opinião de alunos com e sem deficiência física sobre o uso de Exergames em aulas de Educação Física. In: ENCONTRO DA ASSOCIAÇÃO BRASILEIRA DE PESQUISADORES EM EDUCAÇÃO ESPECIAL, 8., 2013. Londrina. Anais... Londrina: Associação Brasileira de Pesquisadores em Educação Especial, 2013. P. 1529 - 1541. Disponível em: <http://www.uel.br/eventos/congressomultidisciplinar/pages/arquivos/anais/2013/AT032013/AT03-010.pdf >. Acesso em 12 jun. 2014.

SILVA, F.C.T. Realidade virtual não imersiva: contribuição do jogo de videogame como recurso pedagógico nas aulas de Educação Física, 2014. Dissertação (Mestrado em Educação)- Faculdade de Filosofia e Ciências, da Universidade Estadual Paulista - UNESP - Campus de Marília, 2014. Disponível em:

http://www.marilia.unesp.br/Home/PosGraduacao/Educacao/Dissertacoes/silva fctd me mar.pd $\underline{\mathrm{f}}>$. Acesso em 12 Jun. 2014.

TEIXEIRA, M.S.; FIGUEIREDO, J.S. Manual teórico-prático de recreação para todos. São Paulo: Obelisco, 1970.

VAGHETTI, C. A. O.; BOTELHO, S. S. C. Ambientes virtuais de aprendizagem na Educação Física: uma revisão sobre a utilização de Exergames. Ciências e Cognição, v. 15, n. 1, p. 76-88, 2010. Disponível em; < http://www.cienciasecognicao.org/revista/index.php/cec/article/view/292/162 $>$. Acesso em 12 jun. 2014. 